\title{
Investigation and Thinking about the Aquatic Product Processing Industry in Fuzhou under the Background of Blue Economy
}

\author{
Guo Changning ${ }^{1,2}$, Yang Jianzhou ${ }^{1 *}$ \\ ${ }^{1}$ School of Economics for Fujian Agriculture and Forestry University \\ Fuzhou of Fujian 350002 \\ ${ }^{2}$ School of Management for Fujian University of Technology \\ Fuzhou of Fujian 350108
}

\begin{abstract}
As an important part of marine economic development in Fuzhou, how to integrate aquatic products processing industry into the construction of "Belt and Road", promote the development of blue economy, and create a strong city of marine economy at a higher starting point should gain more attentions. This article combines the department interviews, the panel discussion with entrepreneurs, and questionnaire investigation. Based on the development status of aquatic product processing industry in Fuzhou, this paper adopts "Porter's diamond model" to conduct systematic analysis on the development factors of aquatic product processing in Fuzhou, and puts forward several countermeasures and suggestions for the development of aquatic product processing industry in Fuzhou.
\end{abstract}

Keywords-Blue economy; Aquatic product processing in Fuzhou; Development factors; Countermeasures and suggestions

\section{INTRODUCTION}

Fuzhou is an important portal for the marine silk rod, and also an important aquatic product collecting and distributing center and consumption city nationwide; the aquatic product processing industry plays an important role in promoting economic growth and realizing the increase of incomes among residents, etc [1]. In the face of the new economic development rend and task, as an important component for marine economic development in Fuzhou, how to integrate aquatic products processing industry into the construction of "Belt and Road", create a strong city of marine economy and construct "Offshore Fuzhou" is a realistic problem that should be noticed.

\section{The Current Aquatic Product Processing INDUSTRY IN FUZHOU HAS AN OVERALL SOUND DEVELOPMENT}

Since the reform and opening-up of last century, the aquatic product processing industry in Fuzhou City has relied its own regional advantages, successively established a big batch of aquatic product processing enterprises and introduced lots of aquatic product processing and manufacturing equipment under the support of all levels of policies for inviting outside investment, and the products thereof including surimi-based products, roasted eel, prawn series of products, and seaweeds processing products are well sold in Japan, America, Korea, Russia, European Union, Southeast Asia and other countries and regions, with good market sales and development prospect

\section{A. The Gross Scale can Rank Top in the Entire Province}

The aquatic product processing industry in Fuzhou has a good development momentum and the scale is constantly expanded. In 2017, there were 98 aquatic product processing enterprises, and 22,000 employees; the total processing volume was 1.427 million tons, which was increased by $10.7 \%$ the output value was RMB 28.52 billion, which was increased by $9.7 \%$, occupying $11.2 \%$ of the total output value of marine economy in the entire city [2]. The aquatic product processing industry in Fuzhou keeps a leading position in the entire province, and its total processing volume and processing output value respectively occupy $45 \%$ and $32 \%$ of the entire province; the processing output value, export delivery value, sales incomes and other indexes rank the second in the entire province.

\section{B. The Regional Industrial Agglomeration Effect is Obvious}

Along with Fujian strategy of "eastward expansion and southward advance, along the river and facing the sea" being promoted and the big development of port-surrounding industry, the centralization degree for aquatic product processing industry is constantly improved, and is now forming three big aquatic product processing industrial groups, including Fujian Provincial Western Shore (Lianjiang) Aquatic Product Processing Base, Fuqing Longtian Aquatic Product Processing Park and the Aquatic Product Processing Base around Minjiang (Mawei-Kuaian-Chang'an Aquatic Product Processing Corridor-Changle), of which the total processing quantity of aquatic products in Lianjiang County-"the County of Abalone in China" has ranked the first in the entire province and the second nationwide considering county-level for several years continuously, and the annual output of abalone can reach to above 30,000 tons, occupying $1 / 3$ of the amount nationwide. The prawn processing in Guzhou City is 
centralized in Fuiqng Longtian Aquatic Product Processing Park, and becomes the first batch of "modernized fishery industrial parks in Fujian Province".

\section{Strong Brand Creation and Scientific Innovation Capacity}

The aquatic product processing industry in Fuzhou City adheres to integrity management and quality first. According to the investigation data of 80 aquatic product processing industries, $71.3 \%$ of enterprises obtained European Union Registration and ISO quality authentication, $41.3 \%$ of enterprises promoted HACCP international quality management standard, and $20 \%$ of enterprises obtained SSOP or GMP qualification recognition. Under strict quality control management system, the brand construction achievements for aquatic products in Fuzhou City were good, and 9 enterprises have been rated as Chinese famous brand, Chinese famous agricultural product brand or Chinese famous trademark in the entire city, and 4 special varieties obtained national geological mark protection product or national geological mark certification trademark, and 2 enterprises obtained organic food or green food title. Adhere to relying on scientific and technical progress to gradually realize the transformation from initial processing to refined, deep and fine processing on the basis of order production materials for processing.

\section{Good Variety Advantage and Market Expansion Capacity}

According to the investigation, the sales incomes for aquatic product processing industry in Fuzhou City was RMB 28.24 billion in 2017 , which was increased by $11.9 \%$ on a year-on-year basis; the export delivery value was RMB 884,000 , which was increased by $7.3 \%$ on a year-on-year basis. Surimi-based products, roasted eel, abalone, prawn and other main processing products are famous at home and abroad. For instance, the export volume of Fuzhou Roasted Eel can occupy about $45 \%$ nationwide, ranking top. The aquatic product processing industry in Fuzhou is still focused on exportoriented processing production, and supplemented by domestic sales, to play the maximum effect of products, actively participate in various exhibitions and expos at home and abroad, and expand the market occupation rate of products at home and abroad. Currently, the sales proportion of aquatic products in the market inside and outside of the province and the overseas market is respectively $27.6: 34.3: 38.1$.

\section{REFLECTION OF THE AQUATIC PRODUCT PROCESSING ENTERPRISES IN FUZHOU CONSIDERING INDUSTRIAL \\ DEVELOPMENT}

Since the beginning of this century, although the aquatic product processing industry in Fuzhou has developed, it is not ideal as a whole, especially after China joined WTO and the occurrence of international financial crisis, the aquatic product processing industry in Fuzhou has faced lots of difficulties and problems, and restricted the future survival and development. In order to understand the reflection of aquatic product processing enterprise about the current industrial operation conditions, this article caries out questionnaire investigation about aquatic product processing enterprises above state designated scale [3].

\section{A. Quantity of Investigation Samples}

According to the data, there were 98 aquatic product processing enterprises above state designated scale in 2017, and this time, totally 80 enterprises were successfully investigated, the industrial segmentation is as follows: 39 aquatic product cooling processing enterprises, 29 surimibased products and aquatic product dry-salted product enterprises, 9 aquatic feed manufacturing enterprises, 1 fish oil extraction and product manufacturing enterprises, and 2 health care production enterprises.

\section{B. Reflection on the Questionnaire Investigation of Enterprises}

This investigation totally involves three parts of contents, including the basic conditions about the enterprise, the staged evaluation and analysis of enterprise development, enterprise expectation, opinions and suggestions. The investigation result shows that: aquatic product processing enterprises in Fuzhou are optimistic about the future development opportunities, but simultaneously, their reaction towards the international and domestic political environment, economic downturn pressure and the enterprise operation difficulty factors, and can basically meet objective reality.

1) Enterprises are Optimistic about the Industrial Development Opportunities as a Whole

With respect to the future industrial development opportunity factors, among 80 interviewed enterprises, $37.5 \%$ of enterprises think that this is good, and $57.5 \%$ of enterprises think that this is general, and merely $5.1 \%$ of enterprises think that it is unsatisfied or extremely unsatisfied.

\section{2) Cost and other Factors Influence Enterprise} Development

With respect to the judgment about the cost factors influencing the enterprise development, $68.8 \%$ of enterprises recognize the fast increase in the cost of raw and auxiliary materials, $42.5 \%$ of enterprises express that there are in short of labor force, $41.3 \%$ of enterprises recognize the lack of capital input, and $31.3 \%$ of enterprises feel the insufficiency of raw materials.

3) Fierce Competition in the same Business and Relatively Big Operation Pressure

With respect to factors of enterprise strategy and horizontal competition, $85 \%$ of enterprises think that the industrial competition is way to fierce; with respect to the factor of market demand, $78.8 \%$ of enterprises feel the bad economic environment and insufficient orders; with respect to the factors of relevant and supportive industries, $37.5 \%$ of enterprises express the shrinkage of aquaculture space, $32.5 \%$ of enterprises express the unsound industrial information and $12.5 \%$ of enterprises express the serious sea water pollution. 
4) It is expected that the Government can Accelerate Tax Revenue and Other Support Strength

For work that requires government support, $75 \%$ of enterprises hope to obtain tax reduction and exemption support, $68.8 \%$ of enterprises hope to provide special financial fund, $60 \%$ of enterprises hope to obtain bank loan and $32.5 \%$ of enterprises hope to provide technical innovation information and scientific and technical cooperation platform.

\section{ANALYSIS ON THE DEVELOPMENT FACTORS OF} AQUATIC PRODUCT PROCESSING INDUSTRY IN FUZHOU

Although the aquatic product processing industry in Fuzhou City has its own unique advantages, and has obtained certain effect, in light of the development prospect, planning and development requirements, there are still big differences, especially when being compared with aquatic product processing developed regions, such as Zhoushan, Yancheng, and Dalian, the integrity of industrial chain, overall scale, market prospect, and regional comprehensive competitiveness thereof are relatively weak, with unbalanced self-development, few highly-valued products, relatively insufficient resources, higher production cost, conservative and old marketing strategies, overall competitiveness to be improved and other difficulties and problems. This article refers to the theoretical system of "Porter's diamond model", emphasizes on discussing about four key factors and two auxiliary factors, gradually analyzes the six factors of production factors, demand conditions, relevant industries and supportive industries, enterprise strategy, enterprise structure and horizontal competition, opportunities, and government, so as to comprehensively improve the recognition on the development factors of aquatic product processing industry in Fuzhou.

\section{A. Analysis on Production Factors}

Fuzhou has unique advantages for developing aquatic product processing industry: it has rich marine biological resources, and the species can reach to 1,580; it covers a big sea area, of which 1,116.07 square kilometers of shallow sea area suitable for aquaculture; there are three big and good deep-water harbor, including Luoyuan Bay, Fuqing Bay and Mawei Port, which can create superior geological traffic conditions for the export trade of aquatic products. However, the overall utilization rate of marine resources isn't high, and the aquatic product resources are relatively deficient; being influenced by economic downturn pressure, salary, the pressure is bigger considering the increase in salary, raw materials and the cost of other production costs.

\section{1) Not High Aquatic Product Resource Development Utilization Rate}

Although Fuzhou City has rich marine resources, it is merely restricted to the development of coastal zone and adjacent sea, mainly including shallow sea mudflat aquaculture and adjacent sea fishing, and it has formed a certain scale of breeding base and fishery production. On one hand, along with the development of harbor industry, the traditional aquatic product aquiculture area in Fuzhou City will face overall withdrawal (such as Luoyuan Bay) risk in the future, while the aggravation of industry, agricultural and domestic pollutions has caused the decrease in the water quality of aquatic product aquiculture area, caused the decrease in the productivity and quality of aquatic products, and also directly influenced the supply of raw materials for aquatic product processing enterprises. On the other hand, being restricted by insufficient funds and backward technologies, the ocean development in Fuzhou City is merely under the trial stage, with almost no deep-sea operation, and restricted exploitation force. The insufficient resources will directly influence the production and development of aquatic product enterprises. According to the investigation data, $31.3 \%$ of interviewed enterprises express that the supply of raw materials cannot meet the production and development demand of enterprises. According to the introduction of insiders, since the ocean fishing technology is backward, when being compared with Zhoushan, Yancheng, Weihai and other big cities of aquatic products, the scale of aquatic product resources in Fuzhou City is very weak, and this has made enterprises import partial raw materials from Chile and other countries through ocean transportation, which has increased the cost of transportation, refreshment, etc., and decreased enterprise profits.

2) Relatively Big Pressure for the Increase in Raw and Auxiliary Materials, Salary and Other Production Costs

As a labor-intensive industry, salaries and the expenditures of raw and auxiliary materials are the two big important costs of aquatic product processing industry. From 2010 to the present, the annual average increase in the purchasing price for the raw and auxiliary materials of aquatic products is between $30 \%$ and $50 \%$, and the annual amount of increase in salary exceeds $30 \%$, which has caused the straight increase in the production cost of the industry. For instance, the price of eel, the main production raw material for eel processing industry was increased to RMB 100,000/ton in 2017 from RMB $70,000 /$ ton in 2010 , and the annual average increase was $7.4 \%$, and this has caused the decrease in the processing quantity of eel over the recent years.

\section{B. Analysis on the Market Demand Factors}

Currently, the international aquatic product market is synchronously diversified, and the economy in developed markets such as Europe and America tends to be stable and emerging consumption markets such as Russia is fast growing; the world's overall demand for aquatic product consumption is still very strong, which has provided favorable conditions for the aquatic product processing industry in Fuzhou to expand diversified market and optimize export structure. With respect to the domestic market, along with the release of the policy of actively expanding domestic demand as well as the growth of disposable incomes for urban and rural residents in our country and the conversion of consumption concept, the demand quantity for aquatic products, especially prawn, crab and other high-grade fishes, and according to the data of State Statistics Bureau, over the recent ten years, the annual consumption of aquatic products per capita for urban and rural residents' families nationwide can occupy about $6.5 \%$ of the total expenditures, and the annual increase in the consumption of aquatic products per capita is $2.8 \%$, providing a broad space for the development of aquatic product processing industry in Fuzhou. 


\section{Analysis on the Strategic Factors of the Enterprise}

Recently, although the aquatic product process industry in Fuzhou is effective in brand creation and quality control, there are still many problems in the enterprise level, such as oldfashioned production sales mode, insufficient technical innovation and slow market expansion steps, and this indicates that the operation and marketing mode, technical innovation, organization strategy and other aspects remain to be improved for aquatic product enterprises in Fuzhou. This can be specifically reflected as follows:

\section{1) Relatively Backward Profound Development Technology}

The technical development level for aquatic product processing industry in Fuzhou is uneven, and some aquatic product intensive processing technologies haven't obtained important breakthroughs. Since there is no bigger promotion in the technical level of production orders as per the requirements of clients, this has restricted the entire aquatic product processing industry in further expansion and the promotion of competitiveness. Meanwhile, most aquatic products processing in Fuzhou are mostly raw materials, semi-finished products and other modes; marine biology chemistry, pharmacy, health care products and other products with high economic additional value have low development strength, so this has caused a big waste of raw materials, and the production cost cannot be validly controlled. Although some processing enterprises in Fuzhou City can rank top nationwide considering the output and output value of roasted eel, surimibased products, kelp, etc., under the influence of lower development technologies, the enterprise scale cannot be expanded, for instance, among 80 interviewed enterprises, the output value for merely $22.5 \%$ of enterprises was above RMB 500 million, with big distance with enterprises in developed areas. According to the questionnaire investigation data, it can also show that: $53.9 \%$ of enterprises input zero in scientific and technical innovation, the scientific and technical input in $38.8 \%$ of enterprises can occupy less than $10 \%$ of the main business incomes, and $6.3 \%$ of enterprises' scientific and technical input can occupy $10 \%-30 \%$ of the main business incomes.

\section{2) Relatively Conservative Operation Strategies}

Along with the state further expands reform and openingup, lots of enterprises are affected by exchange rate fluctuation, trade barrier and the manufacturing industry expansion and promotion of surrounding developing countries as well as other factors, and the export profit space for aquatic product processing enterprises is increasingly narrow. Lots of aquatic product processing enterprises in Fuzhou adopt conservative operation strategies, to adapt to the bad influence of international financial crisis and other big environments on enterprises. In the export sales market, due to the consideration of enterprises in big investment cost, high defensive risk and other aspects, the confidence for adopting the investment strategy of "going out" is insufficient, so most of them adopt the mode of "forcing prices down, keeping old clients + exhibiting and finding new orders", and attempt to obtain small profits but quick turnover, maintain production, and finally, it is very difficult to make enterprises bigger and stronger. However, as for the domestic sales, since the management expenses and marketing cost expenses for independently expanding domestic terminal consumption market are huge, lots of aquatic product processing enterprises in Fuzhou adopt the mode of "contract sales agent + order sales in batches + e-commerce retail". With respect to the future development direction of expanding market share in enterprises, according to the investigation data, $20 \%$ of enterprises tend to exploit overseas market, $51.3 \%$ of enterprises tend to expand domestic market, and $28.7 \%$ of enterprises tend to the simultaneous development of domestic and overseas market. All of these will form certain restrictions for aquatic product processing enterprises in expanding domestic and overseas market.

\section{Analysis on the Relevant and Supportive Industry Factors}

In the recent years, the fishery economy in Fuzhou has developed fast, and ocean fishery has also been constantly expanded, the output and output value can reach to 227,900 tons and RMB 2.215 billion respectively, ranking the first nationwide considering the annual output; aquaculture is intensive and high-efficient, aquaculture enterprises can go to the sea boldly, and both the aquaculture scale outside of the province and the beyond the borders have been largely increased; the aquatic product processing circulation was accelerated and more efficient, Mawei Strait Aquatic Product Transaction Center has become the biggest marine product transaction market nationwide, and the annual trading volume is about 2000,000 tons; while the trial operation of ChinaASEAN Marine Product Exchange has promoted the conversion of aquatic product transaction mode from traditional "berth economy" to "seat economy", and promoted the matching industries related to aquatic product processing industry, such as logistics, cooling chain, fishery science and technology to reach a new level.

\section{E. Analysis on Opportunities and Government Factors}

Currently, the effective approach to realize the fast development of aquatic product processing industry is to utilize ocean fishery resources, and expand the scale of materials for processing. Although Fuzhou has released opinions about constructing "offshore Fuzhou" and preferential policies, and adopted certain reward measures, when being compared with developed countries of materials for processing such as Dalian, Zhoushan and Yancheng, although the aquatic product processing in Fuzhou has industrial leading processing technology, the development of materials for processing is relatively backward, and as for the reasons, lots of insiders reflect that the hardware and software environment conditions for local investment should be further improved and promoted, such as commodity inspection, customs and convenient port environment, tax, power utilization, transportation and other political environment support, which have a bigger promotion space, so many foreign clients and investors prefer Dalian, Zhoushan, Yancheng and other cities, and it is necessary to think deeply about it. 


\section{F. Analysis on the Overall Competitiveness Expectation}

As the basic industry of marine economy, aquatic product processing industry is located at an important middle link, and plays an irreplaceable role in developing modernized fishery, improving the inner potential of marine economy, and realizing blue marine economy growth pole [4]. Through analyzing on the basis of Porter's diamond model, the aquatic product processing industry in Fuzhou has a good development foundation during the earlier stage for four key factors, including the production factor, demand conditions, relevant industry and supportive industries, enterprise strategy, enterprise structure and horizontal competition, especially the variety of aquatic products, which is full of local characteristics, and the production technology equipment takes a leading position nationwide, and the relevant industrial matching development is sound; enterprises are full of confidence for the future development, especially when facing the currently unprecedented opportunities and political support, providing good conditions for the development of aquatic products in Fuzhou, thus, it can be seen that the future development for aquatic product processing industry in Fuzhou is promising[5]. The aquatic product processing industry in Fuzhou should take advantage of its unique location and marine resource advantages, exert the effect of "the city of fishery brand", overcome disadvantages such as its resource technologies on the basis of long-term development, realize upgrading and transformation, further conduct structural adjustment, truly promote the inner potential of development, practically become the important grasp for implementing "offshore Fuzhou" strategy and new economic growth pole, and make its own due contribution to the lookforward and leaping development in Fuzhou.

\section{Thinking About the Aquatic Product Processing INDUSTRY IN FUZHOU}

The inevitable demand for industrial transformation upgrading is to construct "Offshore Fuzhou", create a strong marine city, and energetically develop aquatic product processing industry. Currently, the aquatic product processing industry in Fuzhou is faced with unprecedented development opportunities, and lots of realistic difficulties and problems, which require the government and enterprises to pay enough attention to it, so as to promote the technical innovation and leaping development of aquatic product processing industry in Fuzhou.

\section{A. Promising Orientation, and Bravely Seizing Unprecedented Development Opportunities}

When working at Fuzhou, Comrade Xi Jinping used to point out that: Along with the opening of "marine silk road" strategy and the practice of Fujian Free Trade Zone, the aquatic product processing industry in Fuzhou is faced with historical development opportunities. How to carry out national marine economic development pilot work as per the requirements of West Coast Economic Zone Development Plan, strive to construct Strait Blue Economy Test Area, Fuzhou City of Fujian Province has released Several Opinions about Accelerating Marine Economic Development and Opinions about Accelerating the Construction of "Offshore
Fuzhou" at a Higher Standing Point, and create a good political environment and development platform for the fast development of aquatic product processing industry in Fuzhou.

\section{B. Sincere Service, Promising and High-efficient Political Guarantee}

In the recent years, all levels of government have successively released the promotion and guarantee measures for the development of aquatic product processing enterprises, so as to promote the development of aquatic product industrialization. However, in practice, lots of political announcement cannot be thoroughly executed, partial assistance projects cannot be implemented in place, and enterprises fail to obtain essential improvement in capital flow, logistics, employment and other service guarantee. Thus, it is requested to practically break through "the last kilometer" in service guarantee, and truly make a difference in supporting and serving enterprises.

\section{Innovation-driven, Creating Aquatic Product Characteristics in Fuzhou}

Under the new normal of current economic development, aquatic product processing industry is like other industries, with constant increase in raw and auxiliary materials and labor cost; besides, the production sales mode are outdated in lots of aquatic product processing enterprises, and this has caused the serious waste of production cost and low additional value, the domestic and overseas market exploitation steps are slowed, without obvious effects, so it is requested to further make endeavors in further technical innovation and structural transformation.

\section{CONCLUSION}

Based on further investigation toward Fuzhou's aquatic product processing industry under the background of Blue Economy, this article finds out that this processing industry has an overall rapid development currently, not only the regional industrial agglomeration effect is obvious, but also possess strong brand creation and scientific Innovation Capacity. Although Fuzhou aquatic products processing enterprises have also made considerable progress under this environment, there are still big differences, especially when being compared with aquatic product processing developed regions, such as the incomplete industrial chain and weak regional competitiveness, with few highly-valued products, higher production cost and conservative marketing strategies. Therefore, it is necessary for government and enterprises to seize the unprecedented development opportunities, set up the consciousness of sincere service, ensure the high-efficient operation of policy and implement innovation-driven mechanism, thus creating the characteristic brand of Fuzhou aquatic products. 


\section{ACKNOWLEDGMENT}

About the Author: Guo Changning (1982- ), male, born in Yanji of Jilin, a Lecturer and Doctoral Candidate, and is engaged in the research of forest ecological economy, (Tel.) 15280405918, (E-mail) 48560220@qq.com.

Corresponding Author: Yang Jianzhou (1965- ), male, born in Quanzhou of Fujian, a Professor and Doctoral Supervisor, and is engaged in the research of resource and environment economy and forestry economy, (Tel.) 0591-87643598, (Email)yjz300@163.com.

\section{REFERENCES}

[1] F.Z. Li, F. Wang, "Study on the path bifurcation of resource dependence in marine food processing industry in Blue Economic Zone," Chin. Fishe. Eco. Beijing, vol. 5, pp. 77-84, May 2014.

[2] M.Y. SUN, M.Q. LI, "The heterogeneous evolution of marine industry structure in Shandong peninsula blue-economic zone," East China Eco. Man. Shanghai, vol. 25, pp. 12-16, March 2015.

[3] J. Beyer, "The same or not the same-on the variety of mechanisms of path dependence,” Inte. Journa. Soc. Sci. New York, vol. 15, pp. 3-11, Aguest 2016.

[4] M. Wang, L.Q. Ma, "Integration of fishery industrial chain based on sustainable development in China," Agri. Econom. Man. Beijing, vol. 2, pp. 13-19, February 2015.

[5] Y.F. Deng, L.M. Han, "Industrial Value Chain Analysis of Chinese Fisheries," Adva. marin Sci. Beijing, vol. 21, pp. 35-39, November 2016. 